\title{
APLIKASI ROAD EVALUATION AND MONITORING SYSTEM (REMS) ( Studi Kasus : Ruas Jalan Magelang-Yogya, Sta.8+451 S.D Sta.10+000, Kabupaten Magelang, Provinsi Jawa Tengah )
}

\author{
Regi Andrean 1),Ary Setyawan²), Djumari3)
}

\author{
1)Mahasiswa Program Studi Teknik Sipil Fakultas Teknik Universitas Sebelas Maret \\ 2),3) Dosen Program Studi Teknik Sipil Fakultas Teknik Universitas Sebelas Maret \\ Jl. Ir. Sutami 36 A, Kentingan Surakarta 57126, Telp (0271) 647069, Fax 662118
}

Email : regiandrean@gmail.com

\begin{abstract}
The road is a land transportation infrastructure that functions as a link. from one place to another. Evaluation of road pavement must be done regularly to find out the conditions of road pavement. Today's evaluation requires software that can belp make it easier to survey road damage in terms of cost, time, energy and access to road damage survey results. The assessment of pavement conditions can be done using damage analysis using the PCI REMS (Road Evaluation and Monitoring System) method by classification based on the type, level and grade of damage. This method has a more accurate rating scale with a scale of 0-100. To measure accuracy, REMS software will be compared with manual PCI calculations.

Roads that will be examined are the Magelang-Yogya Street Section Sta.8 + 451 - Sta.10 + 000. Magelang, Central Java Province. This research was carried out by dividing 29 segments, starting from STA $8+451$ to STA $10+000$. Each dimension is measured for damage, then the data obtained is entered into the form provided and REMS software is then analyzed by the program. Data that has been filled into REMS software then shows the results of the PCI value. The results of this data will then be synchronized to the REMS server that can be accessed by surveyors or those who have registered on the infrasoft.id website (server).

The results of the pavement surface evaluation of Jalan Magelang-Yogya STA $8+450$ to STA $10+000$ using the PCI Manual method yielded a value of 53.72 with the category of "Poor". The calculation results of the Pavement Condition Index (PCI) method using the Road Evaluation and Monitoring System (REMS) application on the segment obtained a value of 64.86 with the category "Fair". Comparison of the value of the condition of manual PCI and PCI REMS from a total of 29 segments, obtained 27 segments that have a percentage deviation of more than or equal to 1\% with an average deviation of $11 \%$. PCI REMS values tend to be higher than PCI Manual values. This is due to differences in accuracy in chart reading (DV and CDV) and in the PCI Manual method for selecting CDV values, selected from the highest CDV value but for PCI REMS values are taken with first order $C D V$.
\end{abstract}

Keywords : Pavement Condition Index, REMS, Road Damage

\begin{abstract}
Abstrak
Jalan merupakan sebuah prasarana transportasi darat yang berfungsi sebagai penghubung satu tempat ke tempat yang lain. Evaluasi perkerasan jalan harus dilakukan secara teratur untuk mengetahui kondisi perkerasan jalan. Evaluasi dewasa ini membutuhkan software yang dapat membantu memudahkan dalam survey kerusakan jalan baik dalam aspek biaya, waktu, tenaga maupun akses hasil survey kerusakan jalan tersebut. Penilaian kondisi perkerasan dapat dilakukan dengan menggunakan Analisa kerusakan menggunakan metode PCI REMS ( Road Evaluation and Monitoring System ) dengan penggolongan berdasarkan jenis, tingkat dan kelas kerusakannya. Metode ini memiliki skala penilaian lebih akurat dengan skala 0-100. Untuk mengukur keakuratannya, software REMS akan dibandingkan dengan perhitungan PCI secara manual.

Ruas Jalan yang akan diteliti adalah Ruas Jalan Magelang-Yogya sta Sta.8+451 - Sta.10+000. Magelang, Provinsi Jawa Tengah.Penelitian ini dilakukan dengan membagi 29 segmen yaitu mulai dari STA 8+451 sampai STA 10+000. Tiap kerusakan diukur dimensinya, kemudian data yang diperoleh dimasukan kedalam formulir yang disediakan dan software REMS yang kemudian dianalisa oleh program. Data yang telah diisi kedalam sofware REMS kemudian menunjukkan hasil nilai PCI. Hasil data ini kemudian akan disinkronkan ke server REMS yang dapat di akses oleh surveyor atau pihak yang telah melakukan register ke website infrasoft.id (server). Hasil evaluasi kondisi permukaan perkerasan Jalan Magelang-Yogya STA 8+450 sampai STA 10+000 menggunakan metode PCI Manual menghasilkan nilai sebesar 53,72 dengan kategori "Poor". Hasil perhitungan
\end{abstract}


metode Pavement Condition Index (PCI) dengan menggunakan aplikasi Road Evaluation and Monitoring System (REMS) pada ruas tersebut didapatkan nilai sebesar 64,86 dengan kategori "Fair". Perbandingan nilai kondisi PCI manual dan PCI REMS dari total 29 segmen, diperoleh 27 segmen yang mempunyai pesentase simpangan lebih dari atau sama dengan 1\% dengan simpangan rata-rata sebesar 11\%. Nilai PCI REMS cenderung lebih tinggi dibandingkan Nilai PCI Manual. Hal ini disebabkan karena perbedaan keakuratan dalam pembacaan grafik (DV dan CDV) dan dalam metode PCI Manual untuk pemilihan nilai CDV, dipilih dari nilai CDV paling tinggi tetapi untuk PCI REMS diambil nilai dengan CDV urutan pertama.

Kata Kunci : Pavement Condition Index, REMS, Kerusakan jalan

\section{PENDAHULUAN}

Jalan merupakan sebuah prasarana transportasi darat yang berfungsi sebagai penghubung satu tempat ke tempat yang lain. Jalan memiliki tiga fungsi dasar perkerasan meliputi kenyamanan, keamanan dan efisiensi pelayanan. Kerusakan pada jalan harus diminimalisir agar dapat memenuhi tiga fungsi dasar perkerasan tersebut. Pemeliharaan dan perbaikan jalan baik secara rutin maupun secara berkala perlu dilakukan, untuk menjaga agar tingkat pelayanan jalan tersebut tidak mengalami penurunan serta menjaga keawetan jalan sampai mencapai umur rencana.

Evaluasi perkerasan jalan harus dilakukan secara teratur untuk mengetahui kinerja perkerasan jalan. Evaluasi dewasa ini membutuhkan software yang dapat membantu memudahkan dalam survey kerusakan jalan baik dalam aspek biaya, waktu, tenaga maupun akses hasil survey kerusakan jalan tersebut. Kondisi fungsional dapat dilakukan dengan menggunakan Analisa kerusakan menggunakan metode PCI REMS ( Road Evaluation and Monitoring System ) dengan penggolongan berdasarkan jenis, tingkat dan kelas kerusakannya. Metode ini memiliki skala penilaian lebih akurat dengan skala 0-100.

Jalan Magelang-Yogya, Mungkid, Kabupaten Magelang, Jawa tengah, merupakan ruas jalan nasional di Magelang. Ruas jalan ini merupakan jalan arteri kelas I. Salah satu penelitian menganalisis bahwa ruas jalan ini merupakan daerah rawan kecelakaan (blackspot), salah satu penyebabnya adalah kerusakan pada permukaan jalan seperti rutting, potholes dan lendutan. Kondisi perkerasan jalan yang cukup parah ini mengakibatkan kendaraan tergelincir sehingga banyak terjadi kecelakaan.

Berdasarkan uraian diatas, maka akan dilakukan analisis kerusakan jalan menggunakan REMS ( Road Evaluation and Monitoring System ) yang tersinkronisasi dengan server GIS sehingga biaya, waktu dan tenaga operasional lebih kecil dibandingkan bila dilakukan secara manual.

\section{LANDASAN TEORI}

\section{Pengertian REMS}

REMS merupakan singkatan dari Road Evaluation and Monitoring System. REMS merupakan software yang menggabungkan antara analisa kerusakan jalan PCI (pavement condition index) yang merupakan analisis kerusakan jalan fungsional dan GIS (Geographyc Information System ). Geographyc Information System (GIS) adalah sistem yang dirancang untuk menangkap, menyimpan, memanipulasi, menganalisis, mengelola, dan menyajikan data spasial atau geografis.. Website yg digunakan sebagai server REMS adalah infrasoft.id

\section{Jenis-Jenis Kerusakan Perkerasan Jalan}

Secara garis besar kerusakan dapat dibedakan menjadi dua bagian, yaitu kerusakan struktural, mencakup kegagalan perkerasan atau kerusakan dari satu atau lebih komponen perkerasan yang mengakibatkan perkerasan tidak dapat lagi menanggung beban lalu lintas; dan kerusakan fungsional yang mengakibatkan keamanan dan kenyamanan pengguna jalan menjadi terganggu sehingga biaya operasi kendaraan semakin meningkat (Shahin, 1994).

Menurut Shahin (1994), ada beberapa tipe jenis kerusakan pada perkerasan jalan : 
1. Retak kulit buaya (Alligator Cracking)

2. Keriting (Corrugation)

3. Amblas (Depression)

4. Retak Samping Jalan (Edge Cracking)

5. Joint Reflection Cracking

6. Penurunan bahu pada jalan (Lane)

7. Retak memanjang dan melintang (Longitudinal \& Transfer Cracks)

8. Tambalan pada galian utilitas

9. Lubang (Potholes)

10. Alur (Rutting)

11. Sungkur (Shoving)

12. Weathring/Raveling (pelepasan butir)

\section{METODE PENELITIAN}

Metode penelitian yang digunakan adalah metode deskriptif analitis, yaitu suatu metode penelitian dengan cara mendeskripsikan atau memberi gambaran terhadap suatu objek penelitian yang diteliti melalui sampel atau data yang telah terkumpul dan membuat kesimpulan yang berlaku umum (Soegiyono, 2009). Jenis data yang digunakan merupakan data primer. Tahapan penelitian adalah sebagai berikut.

Mulai REMS

Persiapan Survei

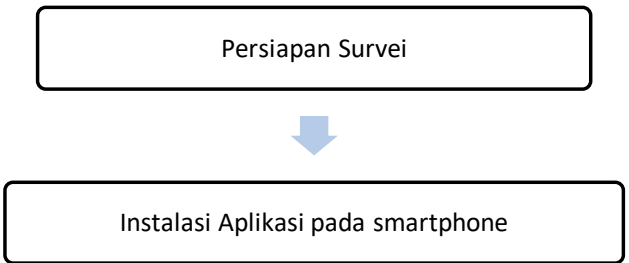

Sinkronisasi Android dengan PC

Proses Survey dengan Aplikasi Android

Analisis $\mathrm{PCl}$ oleh program

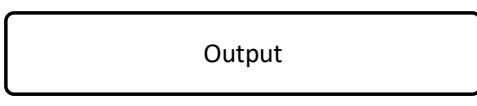

Sinkronisasi Data ke server
Mulai PCI Manual

Menentukan Panjang Total Unit Sampel

Menentukan Jumlah Minimum Unit Sempel

Mengukur Setiap Jenis Kerusakan

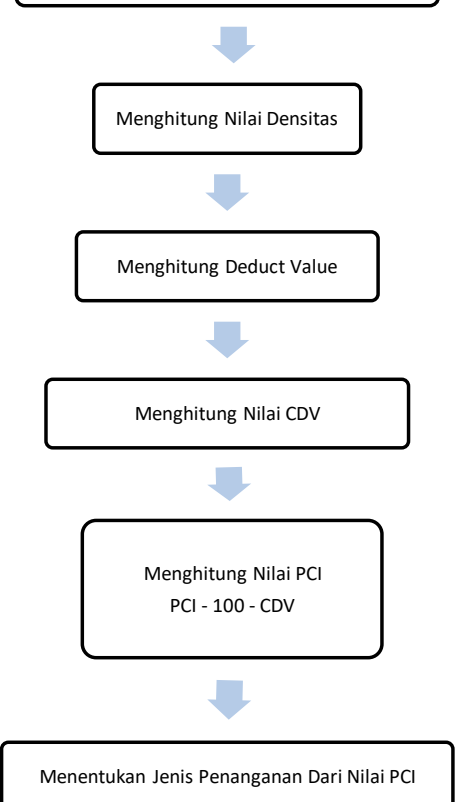

Menentukan Jenis Penanganan Dari Nilai PC

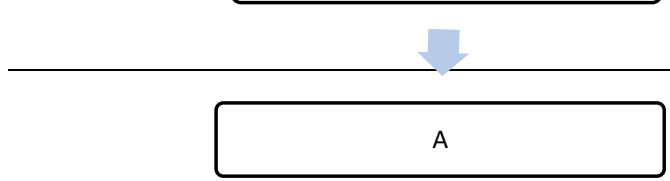




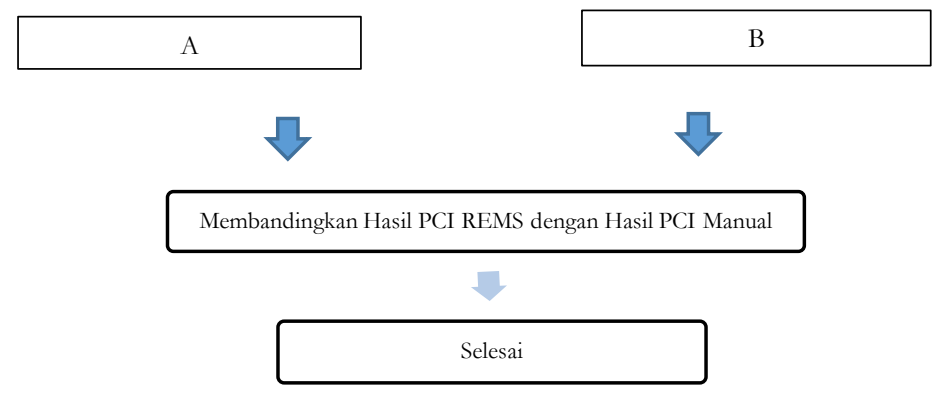

Gambar 1 Diagram Alir Penelitian dengan Membandingkan Hasil PCI REMS dan PCI Manual

\section{HASIL DAN PEMBAHASAN}

Hasil Perhitungan Kondisi Permukaan Jalan dengan Metode Pavement Condition Index (PCI) Manual

Ruas Jalan Magelang - Yogya merupakan ruas jalan yang penghubung antara daerah Magelang dengan Yogyakarta. Jalan ini dikategorikan sebagai Jalan Arteri Kelas I dengan lebar jalan 21 m, memiliki 4 lajur dan 2 arah dan terdapat median. Berikut ini merupakan hasil analisis kerusakan jalan metode PCI secara manual.

Tabel 1 Hasil Perhitungan Nilai PCI Manual Tiap Segmen Ruas Jalan Magelang - Yogya

\begin{tabular}{ccccc}
\hline No. & STA & CDV Maks & PCI & Keterangan \\
\hline $\mathbf{1}$ & $8+451-8+508$ & 62 & 38 & Very Poor \\
\hline $\mathbf{2}$ & $8+508-8+560$ & 50 & 50 & Poor \\
\hline $\mathbf{3}$ & $8+560-8+615$ & 42 & 58 & Fair \\
\hline $\mathbf{4}$ & $8+615-8+670$ & 36 & 64 & Fair \\
\hline $\mathbf{5}$ & $8+670-8+720$ & 68 & 32 & Very Poor \\
\hline $\mathbf{6}$ & $8+720-8+773$ & 69 & 31 & Poor \\
\hline $\mathbf{7}$ & $8+773-8+824$ & 58 & 42 & Very Poor \\
\hline $\mathbf{8}$ & $8+824-8+875$ & 70 & 30 & Satisfactory \\
$\mathbf{9}$ & $8+875-8+925$ & 18 & 82 & Poor \\
\hline $\mathbf{1 0}$ & $8+925-8+979$ & 51 & 49 & Serious \\
\hline $\mathbf{1 1}$ & $8+979-9+035$ & 83 & 17 & Very Poor \\
\hline $\mathbf{1 2}$ & $9+035-9+089$ & 64 & 36 & Pery Poor \\
\hline $\mathbf{1 3}$ & $9+089-9+145$ & 66 & 34 & Pery Poor \\
\hline $\mathbf{1 4}$ & $9+145-9+199$ & 59 & 41 & Failed \\
\hline $\mathbf{1 5}$ & $9+199-9+256$ & 67 & 33 & Very Poor \\
\hline $\mathbf{1 6}$ & $9+256-9+305$ & 100 & 0 & Poor \\
\hline $\mathbf{1 7}$ & $9+305-9+357$ & 74 & 26 & Poor \\
\hline $\mathbf{1 8}$ & $9+357-9+410$ & 45 & 55 & Serious \\
\hline $\mathbf{1 9}$ & $9+410-9+461$ & 59 & 41 & Fair \\
\hline $\mathbf{2 0}$ & $9+461-9+516$ & 83 & 17 & Satisfactory \\
\hline $\mathbf{2 1}$ & $9+516-9+574$ & 32 & 68 & Good \\
\hline $\mathbf{2 2}$ & $9+574-9+624$ & 24 & 76 & 100 \\
\hline $\mathbf{2 3}$ & $9+624-9-678$ & 0 & & \\
\hline
\end{tabular}




\begin{tabular}{ccccc}
\hline $\mathbf{2 4}$ & $9+678-9+728$ & 7 & 93 & Good \\
\hline $\mathbf{2 5}$ & $9+728-9+778$ & 4 & 96 & Good \\
\hline $\mathbf{2 6}$ & $9+778-9+833$ & 14 & 86 & Good \\
\hline $\mathbf{2 7}$ & $9+833-9+891$ & 10 & 90 & Poor \\
\hline $\mathbf{2 8}$ & $9+891-9+948$ & 15 & 85 & Satisfactory \\
\hline $\mathbf{2 9}$ & $9+948-10+000$ & 12 & 88 & Good \\
\hline
\end{tabular}

$\mathrm{PCI}=\frac{\Sigma P C I_{(s)}}{N}$

dengan :

PCI : Nilai PCI perkerasan keseluruhan.

$\mathrm{PCI}_{(\mathrm{s})} \quad$ : Pavement Condition Index untuk tiap unit.

$\mathrm{N} \quad$ : Jumlah unit.

$$
\begin{aligned}
\text { PCI } & =\frac{\Sigma P C I}{N} \\
\text { PCI } & =\frac{1558}{29} \\
\text { PCI } & =53,72 \text { (Poor } / \text { Buruk) }
\end{aligned}
$$

Hasil Survey Kondisi Permukaan Jalan dengan Metode Pavement Condition Index (PCI) Menggunakan Road Evaluation and Monitoring System (REMS)

Hasil data $P C I$ yang sudah diinput menggunakan REMS akan langsung dianalisis dan hasilnya dapat dilihat di website Infrasoft Indonesia. Berikut merupakan tampilan dari hasil analisis PCI oleh REMS

\begin{tabular}{cccc}
\hline Segmen & $\boldsymbol{P C I}$ & Segmen & $\boldsymbol{P C I}$ \\
\hline $\mathbf{1}$ & 47,996 & $\mathbf{1 6}$ & 15,983 \\
\hline $\mathbf{2}$ & 58,541 & $\mathbf{1 7}$ & 41,786 \\
\hline $\mathbf{3}$ & 67,769 & $\mathbf{1 8}$ & 65,628 \\
\hline $\mathbf{4}$ & 73,453 & $\mathbf{1 9}$ & 50,459 \\
\hline $\mathbf{5}$ & 53,921 & $\mathbf{2 0}$ & 30,669 \\
\hline $\mathbf{6}$ & 42,481 & $\mathbf{2 1}$ & 80,976 \\
\hline $\mathbf{7}$ & 54,260 & $\mathbf{2 2}$ & 85,467 \\
\hline $\mathbf{8}$ & 42,964 & $\mathbf{2 3}$ & 99,617 \\
\hline $\mathbf{9}$ & 100 & $\mathbf{2 4}$ & 89,444 \\
\hline $\mathbf{1 0}$ & 57,139 & $\mathbf{2 5}$ & 96,334 \\
\hline $\mathbf{1 1}$ & 27,143 & $\mathbf{2 6}$ & 69.26 \\
\hline $\mathbf{1 2}$ & 59,338 & $\mathbf{2 7}$ & 93,291 \\
\hline $\mathbf{1 3}$ & 43,883 & $\mathbf{2 8}$ & 89,485 \\
\hline $\mathbf{1 4}$ & 52,083 & $\mathbf{2 9}$ & 91,839 \\
\hline $\mathbf{1 5}$ & 44,135 & & \\
\hline & Total & $\mathbf{1 , 6 5 6 , 2 5 3}$ & \\
\hline & & & \\
\hline & & & \\
\hline & & & \\
\hline
\end{tabular}

Tabel 2 Hasil analisis PCI menggunakan software REMS

PCI $=\frac{\Sigma P C I}{N}$

dengan :

PCI : Nilai PCI perkerasan keseluruhan. 


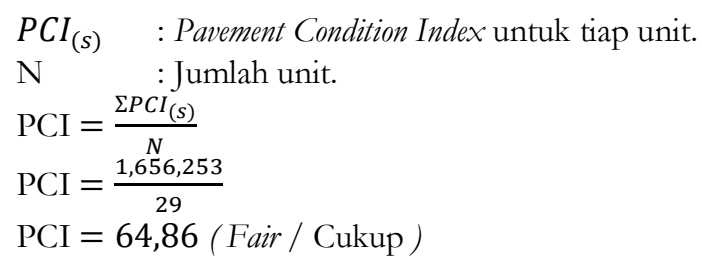

Perbandingan Hasil Analisis Pavement Condition Index (PCI) Manual dan Pavement Condition Index (PCI) Menggunakan Road Evaluation and Monitoring System (REMS)

Hasil dari analisis Pavement Condition Index (PCI) secara manual kemudian dibandingkan terhadap hasil analisis Pavement Condition Index (PCI) dengan menggunakan aplikasi REMS. Kedua hasil ini dibandingkan untuk mengetahui apakah adanya korelasi dan keakuratan perhitungan nilai PCI yang dianalisis dengan REMS. Berikut adalah perbandingan antara keduanya:

a. Nilai PCI manual untuk ruas jalan Magelang - Yogya sebesar 53,72 dengan kategori kerusakan "Poor".

b. Nilai. PCI yang dianalisis dengan REMS untuk ruas jalan Magelang - Yogya sebesar 64,86 dengan kategori kerusakan "Fair".

\section{Grafik Perbandingan REMS dengan PCI Manual}

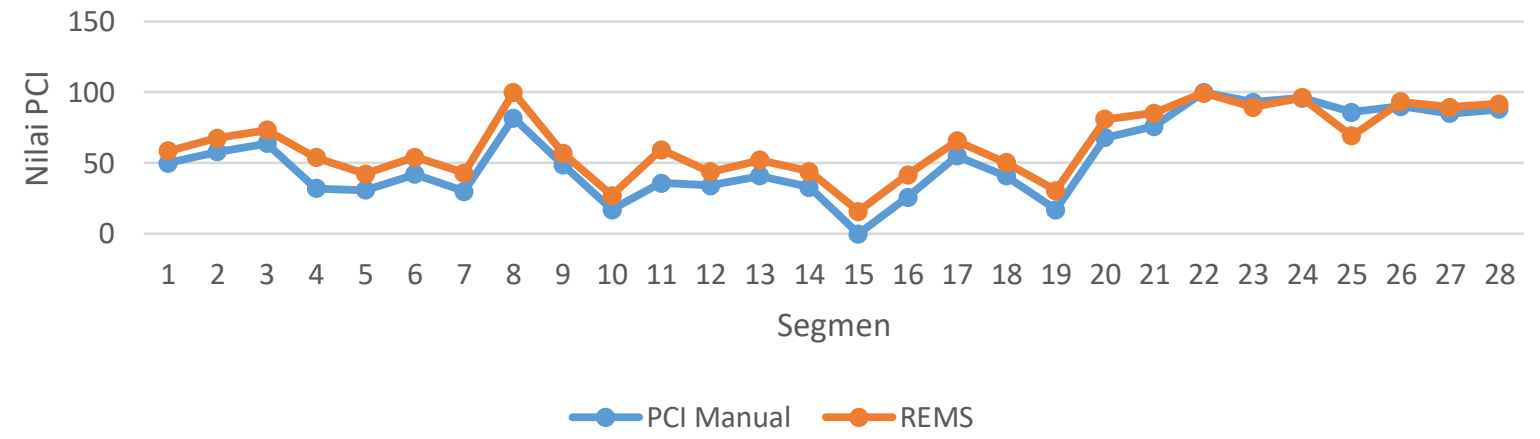

Gambar 2 Grafik Hasil Analisis PCI Manual dan REMS

Hasil perbandingan antara hasil PCI Manual dengan hasil PCI REMS diperoleh simpangan rata-rata sebesar 11\% dimana nilai PCI REMS cenderung lebih tinggi dibandingkan dengan nilai PCI manual.

\begin{tabular}{|c|c|c|c|c|c|c|c|}
\hline STA & No & TOTAL & Q & CDV & $\begin{array}{c}\text { PCI } \\
\text { (CDV Maks) }\end{array}$ & $\begin{array}{c}\text { PCI } \\
\text { (CDV Urutan Pertama) }\end{array}$ & PCI REMS \\
\hline \multirow{2}{*}{ 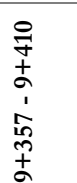 } & 1 & 54 & 2 & 35 & \multirow[t]{2}{*}{55} & \multirow[t]{2}{*}{65} & \multirow[t]{2}{*}{65,628} \\
\hline & 2 & 45 & 1 & 45 & & & \\
\hline
\end{tabular}

Tabel 3 Hasil Pembuktian CDV yg digunakan pada REMS

Pada Tabel 3 Nilai PCI REMS hampir sama dengan Nilai PCI yang dihitung tanpa menggunakan iterasi q sampai $\mathrm{q}=1$ ( CDV urutan pertama/ $\mathrm{q}=2$ ), sedangkan CDV Maks berada pada $\mathrm{q}=1$.

Untuk uji korelasi dengan SPSS diperoleh hasil sebagai berikut:

- Jika nilai Signifikansi < 0,05, maka berkorelasi (Ho ditolak dan Ha diterima).

- Jika nilai Signifikansi > 0,05, maka tidak berkorelasi (Ho diterima dan Ha ditolak).

Dengan hipotesis yang diajukan dalam pembahsan ini adalah

- Ho : PCI REMS tidak berhubungan secara simultan dan signifikan terhadap PCI Manual

- Ha : PCI REMS berhubungan secara simultan dan signifikan terhadap PCI Manual 
Tabel 4 Tabel Korelasi PCI Manual dan PCI REMS

\begin{tabular}{llr|r}
\multicolumn{3}{c}{ Correlations } & \\
& \multicolumn{1}{c}{ PCI Manual } & PCI REMS \\
\hline PCI Manual & Pearson Correlation & 1 & $.936^{* *}$ \\
\cline { 2 - 4 } & Sig. (2-tailed) & 29 & .000 \\
\cline { 2 - 4 } & $\mathrm{N}$ & $.936^{* *}$ & 29 \\
\hline \multirow{2}{*}{ PCI REMS } & Pearson Correlation & .000 & 1 \\
\cline { 2 - 4 } & Sig. (2-tailed) & 29 & 29 \\
\cline { 2 - 4 } & $\mathrm{N}$ & & \\
\hline
\end{tabular}

${ }^{* *}$. Correlation is significant at the 0.01 level (2-tailed).

Pada Tabel 4 didapatkan hasil uji korelasi dengan menggunakan software SPSS dengan nilai Sig. sebesar 0.000 $<0.05$, berarti Ha diterima. Dapat disimpulkan bahwa PCI REMS berhubungan secara simultan dan signifikan terhadap PCI Manual.

\section{KESIMPULAN}

Dari hasil analisis data yang dilakukan pada ruas jalan Magelang-Yogya Sta. 8+451 sampai Sta. 10+000 di Kabupaten Magelang, Jawa Tengah, maka dapat diambil kesimpulan yaitu hasil analisis Metode Pavement Condition Index (PCI) diperoleh nilai sebesar 53,72 atau dalam kategori "Poor" atau "Buruk". Sedangkan hasil analisis PCI menggunakan aplikasi REMS diperoleh nilai sebesar 64,86 dalam kategori "Fair" atau "Cukup". Perbandingan nilai antara PCI manual dan PCI REMS didapat sebanyak terdapat 27 segmen dari 29 segmen memiliki perbedaan simpang yang melebihi $1 \%$ dengan rata rata simpangan sebesar $11 \%$. Untuk uji korelasi didapatkan nilai signifikan $0.000<0.05$ yang berarti PCI REMS berhubungan secara simultan dan signifikan terhadap PCI Manual. Nilai PCI REMS cenderung lebih tinggi dibandingkan Nilai PCI Manual. Hal ini disebabkan karena perbedaan keakuratan dalam pembacaan grafik (DV dan CDV) dan dalam metode PCI Manual untuk pemilihan nilai CDV, dipilih dari nilai CDV paling tinggi tetapi untuk PCI REMS diambil nilai dengan CDV urutan pertama.

\section{REKOMENDASI}

1. Aplikasi REMS untuk penggunaan secara umum sudah cukup membantu karena proses penggunaan yang sangat cepat.

2. Dalam analisis Metode Road Evaluation and Monitoring System (REMS) sebaiknya dilakukan update atau perbaikan pada software dengan mempertimbangkan iterasi CDV.

3. Dari hasil analisis data yang dilakukan pada penelitian, Jalan Magelang-Yogya sebaiknya dilakukan rehabilitasi.

\section{UCAPAN TERIMA KASIH}

Ucapan terima kasih kepada Ir. Ary Setyawan, M.Sc, PhD. dan Ir. Djumari, MT yang telah membimbing dan memberi arahan serta masukan dalam penelitian ini.

\section{DAFTAR PUSTAKA}

Ajad M, Latif. 2015. Evaluasi perkerasan jalan, pemelibaraan dan peningkatan dengan metode analisa komponen beserta rencana anggaran biaya (rab) ruas jalan Sragen - Tangen KM 0+000 - 3+000. Surakarta: Universitas Sebelas Maret Surakarta.

Anonim. 1998. Departemen Pekerjaan Umum - Direktorat Jendral Bina Marga, Spesifikasi. Jakarta. 
Anonim. 2005. Buku Pedoman Penulisan Tugas Akhir. Jurusan Teknik Sipil Fakultas Teknik Universitas Sebelas Maret. Surakarta.

ASTM D 6433 - 07, 2007. Standard Practice for Roads and Parking Lots Pavement Condition Index Surveys. United States: Association of Standard Testing Materials.

Bina Marga. 2011. Pedoman Desain Perkerasan Jalan Lentur, Kementerian Pekerjaan Umum, Jakarta. Bina Marga. 2013. Manual Desain Perkerasan Jalan, Kementerian Pekerjaan Umum, Jakarta

Irzami. 2010. Penilaian Kondisi Perkerasan Dengan Menggunakan Metode Indeks Kondisi Perkerasan Pada Ruas Jalan Simpang Kulim - Simpang Batang. (Magister Tesis, Universitas Islam Riau).

Kurnia S, Diar. 2016. Analisis Kondisi Fungsional Jalan Dengan Metode PSI Dan RCI Serta Prediksi Sisa Umur Perkerasan Jalan. Surakarta: Universitas Sebelas Maret Surakarta.

Setyawan,A.dkk, S. 2017. The Design of Road Evaluation and Monitoring System based on Geographical Information System

Setyowati, S. 2011. Penilaian Kondisi Perkerasan Dengan Menggunakan Metode Pavement Condition Index (PCI), Penigkatan Jalan Dan Perbitungan Rancangan Anggaran Biaya Pada Ruas Jalan Solo - Karanganyar Km 4+400 $11+050$. Surakarta: Universitas Sebelas Maret Surakarta.

Shahin, M.Y. 2002. Pavement Maintenance fot Airports, Roads and Parking Lots (second edition). United States : US Army Corps Of Engineer. 